reported. In $31(12,5 \%)$ of the publications the causative agent for the $\operatorname{ReA}$ was unknown, the diagnosis was made clinically.

Conclusion: In this study, it is aimed to draw attention terminology intricacy and the need for the standardization of the definition of ReA and USpA. It is clear that to standardize the definition of Rea and USpA is necessary. Between 2009-2019 there are reported cases diagnosed as ReA associated with bacterial infections (especially with Clostridium difficile, streptococcus and tuberculosis infections), and viral infections (by a majority with HIV), and parasitic infections. It is not clear if we need to define them classically or define them as USPA. Another important consideration is the necessity of extended laboratory investigations to find out the real causative agent even if the patient is clinically diagnosed with $R e A$. The requirement of the differentiation between $\mathrm{ReA}$ and USpA must be revealed for therapeutic researches.

References:

[1] A proposal for the classification of patients for clinical and experimental studies on reactive arthritis. Pacheco-Tena C, Burgos-Vargas R, Vázquez-Mellado J, Cazarín J, Pérez-Díaz JA. J Rheumatol. 1999 Jun;26(6):1338-46.

[2] The Assessment of SpondyloArthritis International Society classification criteria for peripheral spondyloarthritis and for spondyloarthritis in general. Rudwaleit M, van der Heijde D, Landewé R, Akkoc N, Brandt J, Chou CT, Dougados M, Huang F, Gu J, Kirazli Y, et al. Ann Rheum Dis. 2011;70:25-31.

Disclosure of Interests: None declared

DOI: 10.1136/annrheumdis-2020-eular.6001

\section{AB0678 \\ RISK FACTORS FOR ADVERSE PREGNANCY OUTCOMES IN SPONDYLOARTHRITIS: DISEASE PHENOTYPE AND DISEASE ACTIVITY MAY PLAY A ROLE}

A. R. Cruz-Machado ${ }^{1}$, F. Crisafulli' ${ }^{2}$, M. C. Gerardi ${ }^{2}$, M. Filippini ${ }^{2}$, M. Fredi ${ }^{2}$, R. Gorla ${ }^{2}$, M. G. Lazzaroni ${ }^{2}$, C. Nalli ${ }^{2}$, M. Taglietti ${ }^{2}$, A. Lojacono ${ }^{3}$, C. Zinardini ${ }^{3}$, S. Zatti ${ }^{3}$, L. Andreoli ${ }^{2}$, F. Franceschini ${ }^{2}$, A. Tincani ${ }^{2} .{ }^{1}$ Hospital de Santa Maria, Serviço de Reumatologia e Doenças Ósseas Metabólicas, Lisboa, Portugal; ${ }^{2}$ Spedali Civili Di Brescia, Rheumatology and Clinical Immunology, Brescia, Italy; ${ }^{3}$ Spedali Civili Di Brescia, Obstetrics and Gynaecology, Brescia, Italy

Background: Pregnant patients (pts) with spondyloarthritis (SpA) seem at increased risk for adverse pregnancy outcomes (APO), however limited and conflicting data have been published so far and risk factors for APO in these pts remain poorly understood.

Objectives: To assess APO and identify possible risk factors for those in a cohort of SpA pregnant pts.

Methods: Data on SpA pts prospectively-followed in a pregnancy clinic from 2010 to 2019 were retrospectively analysed before conception and during each trimester. Pregnancies complicated by APO were compared with those that were uneventful for demographic and clinical variables. Active disease was defined as a DAS-28-CRP $>3.2$ or an ASDAS-CRP $\geq 2.1$ according to peripheral or axial dominant disease respectively.

Results: 56 pregnancies (mean age $34 \pm 5$ years; median disease duration 60 months, IQR 24-123) in 47 pts were analysed: 37 psoriatic arthritis, 7 axial SpA, 6 undifferentiated SpA, 3 enteropathic SpA, 2 reactive arthritis and 1 enthesitis-related juvenile idiopathic arthritis. APO were recorded in $23 / 56(41 \%)$ pregnancies: $5(9 \%)$ early miscarriages, $1(2 \%)$ medical abortion (central nervous system malformation), $3(5 \%)$ preterm births ( $\geq 34$ gestational week, all for preterm premature rupture of membranes - PROM); 2 (4\%) PROM; 7 (13\%) small for gestational age newborns (SGA); 3 gestational diabetes and 2 cholestasis of pregnancy. Table 1 displays the comparison between pregnancies with and without APO. A higher number of pts with active disease were detected during the $2^{\text {nd }}$ trimester in both groups, however differences between those were only significant at the $3^{\text {rd }}$ trimester $(p=0.03)$. History of inflammatory bowel symptoms (IBS) was also associated with an increased risk for APO $(p=0.02)$. Although not reaching statistical significance, APO occurred more frequently in pts with a previous use of $>1$ conventional synthetic (cs) or biological (b) disease-modifying antirheumatic drug (DMARD) $(p=0.05)$, suggesting a more difficult to treat phenotype. Likewise, pts with APO were less often treated with low dose aspirin (LDA) during pregnancy.

Conclusion: SGA was the main APO recorded. History of IBS, a more difficult to treat phenotype and the presence of active disease during pregnancy influenced APO in this cohort, reinforcing the need for tight disease control before and during pregnancy. Larger and prospective data are warranted to confirm these results and to assess the potential protective role of LDA.

References:

[1] Molto 2018; Zbinden 2018
Table 1. Differences between patients with and without APO

\begin{tabular}{|c|c|c|c|}
\hline & $\begin{array}{l}\text { Pregnancies } \\
\text { with APO }\end{array}$ & $\begin{array}{l}\text { Pregnancies } \\
\text { without APO }\end{array}$ & $p$ \\
\hline $\mathrm{N}, \%$ & $23,41.1$ & $33,58.9$ & \\
\hline $\begin{array}{l}\text { Maternal age at conception, } \\
\text { mean } \pm S D \text { (years) }\end{array}$ & $33.8 \pm 5$ & $33.8 \pm 4.9$ & NS \\
\hline Hx previous APO - N, \% & $4,17.4$ & $3,9.1$ & NS \\
\hline Disease duration, median (IQR), (months) & $96(36-132)$ & $48(24-96)$ & NS \\
\hline Axial dominant disease $-\mathrm{N}, \%$ & $6,26.1$ & $6,18.2$ & NS \\
\hline Peripheral dominant disease $-\mathrm{N}, \%$ & $11,47.8$ & $20,60.6$ & NS \\
\hline Hx enthesitis $-\mathrm{N}, \%$ & $9,39.1$ & $13,39.4$ & NS \\
\hline Hx dactylitis- N, \% & $5,21.7$ & $11,33.3$ & NS \\
\hline Hx psoriasis- $\mathrm{N}, \%$ & $10,43.5$ & $18,54.5$ & NS \\
\hline Hx uveitis- $\mathrm{N}, \%$ & $1,4.3$ & $4,12.1$ & NS \\
\hline $\mathrm{Hx}$ inflammatory bowel symptoms $-\mathrm{N}, \%$ & $4,17.4$ & 0,0 & 0.02 \\
\hline HLA-B27- N, \% & $8,34.8$ & $7,21.2$ & NS \\
\hline$>1$ cs or bDMARDs before conception - N, $\%$ & $13,56.5$ & $10,30.3$ & 0.05 \\
\hline LDA during pregnancy - N, \% & 7, 30.4 & $17,51.5$ & NS \\
\hline Active disease before conception - N, \% & $5,21.7$ & $2,6.1$ & NS \\
\hline Active disease $1^{\text {st }}$ trimester $-\mathrm{N}, \%$ & $1,4.3$ & $4,12.1$ & NS \\
\hline Active disease $2^{\text {nd }}$ trimester $-\mathrm{N}, \%$ & $6,26.1$ & $5,15.2$ & NS \\
\hline Active disease $3^{\text {rd }}$ trimester $-\mathrm{N}, \%$ & 3,13 & 0,0 & 0.03 \\
\hline
\end{tabular}

Legend: $\mathrm{Hx}$ - history of; NS - non significant.

Disclosure of Interests: None declared

DOI: 10.1136/annrheumdis-2020-eular.3753

\section{AB0679 $\quad$ HEALTH ASSESSMENT IN FEMALE PATIENTS WITH SPONDYLOARTHRITIS: FOCUS ON REPRODUCTIVE SPHERE}

E. De Martino ${ }^{1}$, P. Conigliaro ${ }^{1}$, M. S. Chimenti ${ }^{1}$, P. Triggianese ${ }^{1}$, S. L. Bosello ${ }^{2}$, E. Gremese ${ }^{2}$, C. Iannuccelli ${ }^{3}$, F. R. Spinelli ${ }^{3}$, M. Vadacca $^{4}$, R. Perricone ${ }^{1}$ ${ }^{1}$ University of Rome "Tor Vergata", Rome, Italy; ${ }^{2}$ Catholic University of Sacred Heart of Rome A. Gemelli, Rome, Italy; ${ }^{3}$ University of Rome, La Sapienza, Rome, Italy; ${ }^{4}$ University of Rome Campus Bio Medico, Rome, Italy

Background: SpA patients experience a decreased quality of life due to social emotional and relational life impairment in addition to pain, fatigue and joint damage. Sexual dysfunction (SD) is often neglected by both patients and clinicians although articular and extra-articular manifestations of the disease can decrease the quality of sexual life. Previous findings showed that SD can affect from $27 \%$ to $67 \%$ of patients with rheumatic diseases. Data available on SD in rheumatic patients are poor and primarily focus on male ankylosing spondylitis patients Objectives: The aim of this study is to evaluate, in a group of female SpA patients, the presence of SD, its relationship with extra-articular manifestations and to estimate the correlation between disease activity and sexual activity. Methods: 52 SpA patients (including PsA, IBD-SpA and undifferentiated SpAun-SpA) and 50 healthy controls $(\mathrm{HC})$ were administered the Female Sexua Function Index (FSFI) questionnaire for the analysis of sexual function (score from 0 to 100). SD is defined by a score lower than 26. Disease activity was evaluated through DAPSA and BASDAI. SpA-HAQ and BASFI was also performed to assess functional status

Results: There was a trend for a significantly greater proportion of SD in the patients $(21 \%)$ than the controls $\left.(8 \%), x^{2}(1, N=102)=3.52, p=.06\right)$. Within the different groups, the percentage of those with SD according to the FSFI cut off were $23 \%$ of PsA patients, $25 \%$ of IBD-SpA patients, $11 \%$ of un-SpA patients, and $8 \%$ of healthy controls, however, when the patient groups were analysed separately these differences were not significant, $x^{2}(3, N=102)=4.43$, $p=.22$. Mean scores on the FSFI were lower for the total SpA patients group $\mathrm{t}(100)=2.47, \mathrm{p}=.02$ compared to $\mathrm{HC}$. When scores on the FSFI were analysed separately for each patient group, there was a trend for a significant difference between the groups, $F(3,98)=2.43, p=.07$, and follow up t-tests showed that only the PsA group scored significantly lower than the $\mathrm{HC}, t(100)=2.56, p=.01$ (see Fig. 1). Among the items of the questionnaire, questions regarding sexual desire, lubrication and discomfort were statistically significantly lower scores in patients compared to $\mathrm{HC}$ ( $p=0.001, p=0.009, p=0.02$, respectively). For the overall patient group, the FSFI was significantly negatively correlated with the DAPSA $(r=-.37, p=.008)$, the SpA-HAQ $(r=-.30, p=.03)$ and the BASF $(r=-.30, p=.03)$. Additionally, the PsA group showed a negative correlation between DAPSA scores and FSFI score $(r=-.38, p=.03)$ and the IBD-SpA group had a negative correlation between FSFI score and BASFI $(r=-.80, p$ $=.002$ ).

Conclusion: Overall, the data generally show that SD is more common in SpA patients compared to $\mathrm{HC}$ and that SpA patients score lower on the FSFI. The negative correlations between the FSFI and scores on DAPSA, SpA-HAQ and BASFI suggest that sexual function may be poorer for patients with greater disease activity and poorer functional status. These findings could be due to the number of tender and/or swollen joints as well as chronic pain or fatigue patients 
often experience. A key limitation of this study is the small sample size. Future research will include a larger sample size. SD in patients with rheumatic disease is still a neglected field in clinical practice, however, its assessment could contribute to improved quality of life for patients

Table 1. Clinical characteristics of patients and healthy controls

\begin{tabular}{lcccc}
\hline & PsA & un-SpA & IBD-SpA & HC \\
\hline Age (mean \pm SD) & $50.6 \pm 4.0$ & $43.9 \pm 3.6$ & $46.3 \pm 2-0$ & $52.5 \pm 0.5$ \\
Distribution (N\%) & $31(59 \%)$ & $9(17 \%)$ & $12(24 \%)$ & 50 \\
Age at diagnosis (mean \pm SD) & $40.0 \pm 2.5$ & $35.6 \pm 4.1$ & $40.8 \pm 1.2$ & $/$ \\
DAPSA & $15.1 \pm 9.9$ & $12.2 \pm 9.9$ & $/$ & \\
HAQ & $0.6 \pm 0.5$ & $0.8 \pm 0.5$ & $1.0 \pm 0.7$ & $/$ \\
BASDAI & $0.6 \pm 0.9$ & $0.6 \pm 0.8$ & $5.1 \pm 2.8$ & $/$ \\
BASFI & $16 \pm 16.0$ & $37.8 \pm 26.8$ & $46.7 \pm 21.7$ & $/$ \\
\hline
\end{tabular}

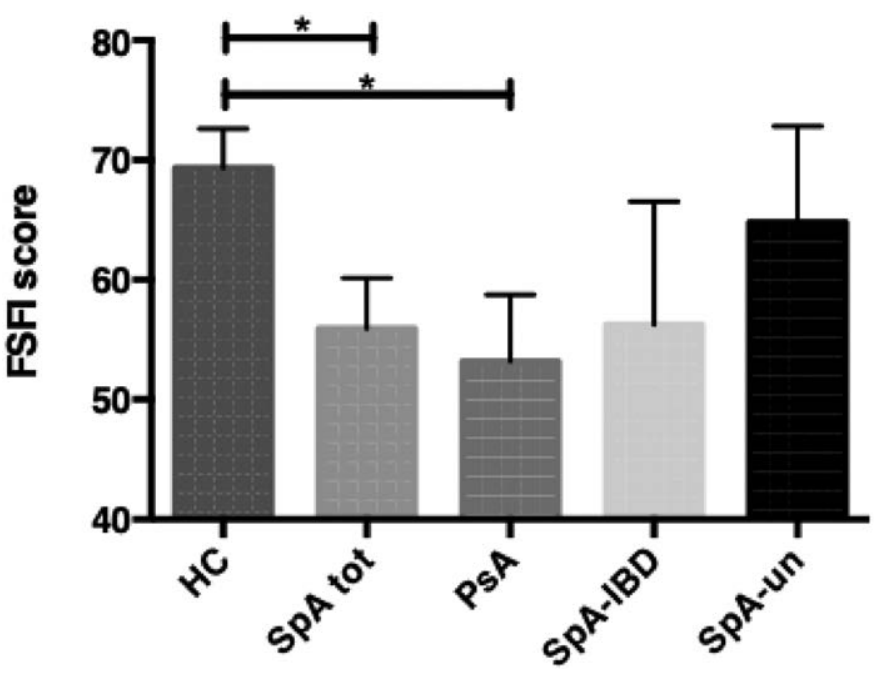

Disclosure of Interests: erica de martino: None declared, Paola Conigliaro: None declared, Maria Sole Chimenti: None declared, Paola Triggianese: None declared, Silvia Laura Bosello Speakers bureau: Abbvie, Pfizer, Boehringer, Elisa Gremese Consultant of: AbbVie, Bristol-Myers Squibb, Celgene, Eli Lilly, Janssen, Merck Sharp \& Dohme, Novartis, Sanofi, UCB, Roche, Pfizer, Speakers bureau: AbbVie, Bristol-Myers Squibb, Celgene, Eli Lilly, Janssen, Merck Sharp \& Dohme, Novartis, Sanofi, UCB, Roche, Pfizer, Cristina lannuccelli: None declared, Francesca Romana Spinelli Grant/research support from: Pfizer, Speakers bureau: Lilly, BMS, Celgene, Marta Vadacca: None declared, Roberto Perricone: None declared

DOI: 10.1136/annrheumdis-2020-eular.4719

\begin{tabular}{|l|l}
\hline AB0680 & BASELINE CHARACTERISTICS OF PATIENTS \\
ENROLLED IN THE ONGOING SIRENA STUDY, \\
A NATIONAL PROSPECTIVE OBSERVATIONAL \\
REGISTRY IN SPONDYLOARTHRITIS SUBJECTS
\end{tabular}

A. Zabotti ${ }^{1}$, A. Gabrielli ${ }^{2}$, C. Selmi ${ }^{3}$, R. D. Grembiale ${ }^{4}$, R. Ramonda ${ }^{5}$, L. Dagna ${ }^{6}$, S. D'angelo ${ }^{7}$, R. Gerli ${ }^{8}$, S. De Vita ${ }^{1}$, S. Marelli ${ }^{9}$, D. Frigerio ${ }^{9}$, E. Favalli ${ }^{10}$ on behalf of the SIRENA Study Group. ${ }^{1}$ S.O.C. Reumatologia, ASUI Santa Maria della Misericordia, Udine, Italy; ${ }^{2}$ S. O.D. Clinica Medica, AOU Ospedali Riuniti, Ancona, Italy; ${ }^{3}$ U.O. Reumatologia ed Immunologia Clinica, IRCCS Istituto Clinico Humanitas ed Università degli Studi di Milano, Rozzano (MI), Italy; ${ }^{4}$ Rheumatology Research Unit, "Magna Graecia" University, Catanzaro, Italy; ${ }^{5}$ U.O.C. Reumatologia, Dipartimento di Medicina DIMED, Università di Padova, Padova, Italy; ${ }^{6}$ U.O. Immunologia, Reumatologia, Allergologia e Malattie Rare, IRCCS Ospedale San Raffaele, Milano, Italy; ${ }^{7}$ Dipartimento Regionale di Reumatologia, AOR San Carlo, Potenza, Italy; ${ }^{8}$ S.C. Reumatologia, Università di Perugia, Perugia, Italy; ${ }^{9}$ Janssen, MAF Immunology, Cologno Monzese (MI), Italy; ${ }^{10}$ S. C. Reumatologia, ASST Gaetano Pini e CTO, Milano, Italy

Background: There is a paucity of epidemiological data in Early Arthritis. SIRENA is an Italian prospective observational study in SpA patients, naïve to conventional, targeted and biological DMARDs.
Objectives: To present the baseline data, including demographic characteristics and patterns of clinical presentation, for the population enrolled between June 2017-February 2019.

Methods: At the study entry, patients are diagnosed, newly or confirmed, according to ASAS criteria and classified in subjects with predominant axial (AX) or with mainly peripheral (PER) manifestations. Diagnostic delay, subtypes of $\mathrm{SpA}$ are evaluated as well as clinical features (i.e. presence of dactylitis, enthesitis, involvement of skin/nails/other organs).

Results: In 23 italian sites, 282 patients were enrolled. Baseline data are shown in Table $1.18 \%$ of the patients were obese (maximum $\mathrm{BMl}=39.7$ ), $22 \%$ over weight. Diagnostic delay was registered for $58.1 \%$ patients with a mean delay of 57.1 months. Main reasons of the delay were incorrect referrals (44\%) and previous misdiagnosis (27\%). The most frequent type of SpA was psoriatic arthritis $(54.3 \%)$, followed by ankylosing spondylitis (18.5\%), undifferentiated SpA (11.5\%), non-radiographic axial SpA (8.2\%), and enteropathic SpA (7.5\%). The majority of patients reported as first symptom peripheral arthritis and inflammatory back pain, followed by enthesitis. The most frequently reported comorbidities were psoriasis $(50.4 \%)$ and cardiometabolic and gastrointestinal diseases (30.1\% and $15.7 \%$,respectively) - Table 2. To the 154 psoriatic arthritis (PsA) patients, CASPAR classification criteria were also applied, with a performance of $95 \%$ and a mean score of 3.64 .

Conclusion: SIRENA is the first Italian Disease Registry for SpA patients. The above results are in line with the few evidences found in literature (1), confirming the representativeness of our sample. In case of PsA, our results confirm that the accordance between ASAS and CASPAR criteria is very high.

\section{References:}

[1] Tayel et al. Rheumatol Int 2012; 32:2837-42.

Table 1.

\begin{tabular}{lc}
\hline & Mean \\
Patient Characteristics (baseline) & $\mathbf{N = 2 8 2}$ \\
\hline Age & 50.8 years \\
Sex (\%) & $49 \mathrm{~F} / 51 \mathrm{M}$ \\
Weight & $73.7 \mathrm{Kg}$ \\
BMI & 25.3 \\
Smoking Status (never/ongoing/past - \%) & $56.8 / 22 / 21.2$ \\
Alcohol consumption (not/occasional/usual drinker - \%) & $50.0 / 44.9 / 5.1$ \\
SpA type (\%) & $35.8 \mathrm{AX} / 64.2 \mathrm{PER}$ \\
Diagnostic Delay (yes - \%) & 58.1 \\
Months of diagnostic delay (mean) & 57.1 months \\
Newly diagnosis (\%) & 68.4 \\
\hline
\end{tabular}

Table 2.

\begin{tabular}{lc}
\hline & Number of Patients \\
A) First Symptom & $N=282$, more than 1 symptom referred \\
\hline Arthritis & 145 \\
Enthesitis & 70 \\
Dactylitis & 35 \\
Inflammatory Back Pain & 114 \\
Psoriasis skin & 67 \\
Psoriasis nails & 21 \\
Uveitis & 5 \\
IBD & 16 \\
B) Comorbidities & Percentage of Patients \\
& $30.1 \%$ \\
Cardiometabolic & $27.0 \%$ \\
- Hypertension & $13.8 \%$ \\
- Dyslipidemia & $7.1 \%$ \\
- Diabetes & $6.0 \%$ \\
- MetS & $3.2 \%$ \\
- CHD & $50.4 \%$ \\
Psoriasis & comorbidity referred \\
Gastrointestinal & $15 \%(5.3 \%$ Crohn's disease $)$ \\
Endocrine & $9.6 \%$ \\
Depression/Anxiety & $5.7 \%$ \\
Osteoporosis & $4.6 \%$ \\
Hepatic & \\
Infections & $3.3 \%(2.5 \%$ NAFLD $)$ \\
Malignancies & $3.9 \%$ \\
Kidney & $2.8 \%$ \\
& $1.8 \%$ \\
&
\end{tabular}

Acknowledgments: This study was sponsored by Janssen Italy. We thank the Investigators and their staff at all of the study sites.

Disclosure of Interests: Alen Zabotti Speakers bureau: Celgene, Novartis, Janssen, Armando Gabrielli Grant/research support from: Pfizer, Speakers bureau: Pfizer, Actelion, Carlo Selmi Grant/research support from: AbbVie, Janssen, MSD, Novartis, Pfizer, Celgene, and Leo Pharma, Consultant of: Bristol-Myers Squibb, Celgene, Eli Lilly, Janssen, Novartis, Pfizer, Roche, and 